\title{
CLARICE LISPECTOR - UMA LEITURA DO SUJEITO
}

\author{
MICHEL PETERSON
}

Para Maria do Carmo Campos

1973: Clarice Lispector publica Água viva. Perto do final desta narrativa fortemente materialista, lemos isto: "Não, nunca fui moderna. $\mathrm{E}$ acontece o seguinte: quando estranho uma pintura é aí que é pintura. E quando estranho a palavra ấ é que ela alcança o sentido."1 Eu gostaria, a partir desta passagem, de me interrogar sobre o estatuto do sujeito feminino na obra de alguém que - dentro do universo do romance brasileiro - mais tem contribuído, desde Perto do coração selvagem, para provocar a ruptura com o psicologismo.

O horizonte filosófico e político que por vezes limitará e abrirá minha leitura será o do debate entre os defensores da modernidade e os da pós-modernidade, debate esse que atinge tanto os países industrializados quanto os considerados em desenvol vimento. ${ }^{2} \mathrm{Na}$ medida em que a condição pós-moderna procura fundamentar a ruína das grandes metanarrativas modernas sobre processos de deslegitimação a fim de pôr em prática uma política que se apóia sobre uma agonística geral (para a qual a literatura fornece, segundo Lyotard, um bom exemplo), podemos pensar que as modalidades narrativas pelas quais se exprime o sujeito tornam-se fundamentais.

Mas o que se constata é que o sujeito feminino continua praticamente fora do debate. ${ }^{3}$ A questão de saber se a mulher - ou, mais exa-

Milchel Peterson. Doutorando pelo Departamento de Literatura Comparada da Universidade de Montreal.

N.E.: O autor năo traduz as citaçőes dos textos em português; o tradutor, no entanto, inclui as dos textos franceses.

1 LISPECTOR, Clarice. Agua viva. 8.ed. Rio de Janeiro, Nova Fronteira, 1986. p.85. Daqui gm diante, as referências a esse texto serão simplesmente seguidas da paginação.

Examinando a coincidência entre o recurso à narrativa das liberdades, a marcha rumo ao progresso e o assumir, por um Estado, da constituição de uma nação, Jean-François Lyotard evoca os problemas modernos de desenvolvimento no Brasil. Ver $O$ pós-moderno. 2.ed. Trad. Rieardo Corréa Barbosa. Rio de Janeiro, Jose Olympio, 1986. nota 107, p.59. A respeito das introduçőes ao debate modernidade/pós-modernidade no Brasil, pode-se ler.Modernidade e 00i-modernidade: uma outra "marcha das utopias" em Pound e Musil. In: ROSENFIELD, Katherin Holzermayr. A linguagem Iberada. São Paulo, Perspectiva, 1989. p.121-8.

I lato apeaar de que alguni toóricos tonham so preocupado com o trabalho feminino na mofermidade e na poss=modernidade, Na virada do soculo, Georg Simmel já se interrogava sobre os elos entre a tragddia da eulari e a disaimetria dos soxos (Ver, a esse respeito, Les cahiers du 
tamente, o sujeito feminino - é moderno ou pós-moderno passa a ser essencial. Esta questão dispensa ingênuas análises de estilo que visariam a dividir a textualidade em masculino e feminino. A questão visa a simplesmente determinar alguns efeitos do feminino na modernidade e na pós-modernidade.

Digamos a princípio: o feminino é parte integrante do projeto moderno ao mesmo tempo em que a emancipação social das mulheres continua sendo um de seus fundamentos. No entanto, se o feminino se inscreve junto à modernidade, por que esta o rejeita? Para compreender este processo devemos voltar aos três últimos capítulos de Le peintre de la vie moderne, de Baudelaire, texto em que se constitui a noção de modernidade. La femme, Éloge du maquillage e Les femmes et les filles aparecem logo após os capítulos dedicados aos anais da guerra, às pompas e solenidades e ao militar. Entre os dois trípticos se inscreve o capítulo sobre o dândi como se aquele que satisfaz suas paixões cultivando "a idéia do belo na (sua própria) pessoa"4 permitisse passar da performatividade fálica à "deliqüescência feminina".

Para Baudelaire, a mulher se dá como um objeto utilizado pelo eu cognitivo do homem a fim de desencadear o processo da imaginação. Ora, este objeto complexo é posto como transcendental. De fato, a mulher é um "ser terrível e incomunicável como Deus" ou, melhor ainda, "uma divindade, um astro que preside a todas as concepções do cérebro macho".5 Trata-se de uma musa que, "mantendo destinos e vontades presos ao seu olhar", 5 não representa nada menos que uma figura mítica, um ídolo. A impossibilidade de comunicação com ela, sentida pelo homem, está ligada ao terror que a mulher lhe inspira. Esta, terrivel e sem piedade por aquele que nela se reflete - apesar de sua "harmonia geral" -, participa do demoníaco e se situa fora da história. Ela aliena o sujeito masculino ao duplo, ao outro que ela representa. É na contemplação horrorizada do feminino especular que o masculino realiza, para falar como Lacan, sua assunção jubilatória. O feminino se torna, para Baudelaire, a raiz das identificações e permite ao masculino a entrada no registro da ficção e o acesso ao simbólico. O paradigma do espelho encerra, por conseguinte, os actantes feminino e masculino num processo de representação (uma estrutura de devolução *) jå que o homem moderno pode então "prospectar o sexo da mulher, procurar aí

GRIF consagrados a Simmel, n.40, primavera 1989). Seguindo à pós-modernidade, deve-se ler os trabalhos frequientemente muito precoces de Linda Hutcheon (particularmente A poetics of postmodernism. History, theory, fiction. New York/London, Routled, 1988) mencionemos, entre outros, o excelente The discourse of others: feminism and posimodernism de Graig Owens, onde são examinadas as modalidades pelas quais os discursos feministas nos obrigan a reconsiderar a questão da alteridade (In: The anti-aesthetic. Essays on postmodern culture.

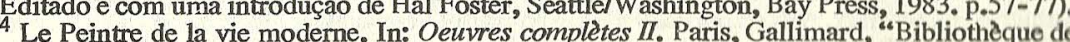
la Pléiade", Paris, 1976. p.710.

${ }^{5}$ Ibid. p. 713 . novas fontes de proveito" $\mathrm{e}$, fazendo isso, "ele fetichiza para antes seu/o desejo". A mulher acompanha assim o homem até o seu ser-fora-de-si, ou seja, até o limite ekstático do Du bist Er! Ela constitui o próprio enigma porque, enquanto origem que reflete as graças da natureza, ela produz a angústia da morte.

O enigma do feminino reside, por conseguinte, no mistério do espelho. Ora, em que consiste precisamente este mistério? Em Água viva Clarice Lispector oferece uma resposta: "Mas o que é um espelho? Não existe a palavra espelho, só existem espelhos, pois um único é uma infinidade de espelhos". Se a palavra "espelho" não existe, \& simplesmente porque, paradoxalmente, o espelho como tal "não é coisa criada e sim nascida" (p.78). Para ser, ele não tem necessidade nenhuma de gesto ou narrativa criadora que o estabeleça na existência. Ele estă, ele existe; nascido, desde sempre estava pronto. Constitui "o espaço mais fundo que existe". É a razão pela qual: "Como a bola de cristal dos videntes, ele me arrasta para o vazio que para o vidente é seu campo de meditação, e em mim o campo de silêncios e silêncios". (p.79). O espelho conduz o feminino à sua própria perda e podemos sugerir que a solução do enigma do feminino reside no modo aporético de sua presença em si e no outro.

Mas por que Baudelaire afirma que a mulher e seu vestido formam "uma totalidade indivisível?" É que a mulher deve, segundo ele, "parecer mágica e sobrenatural". 8 O cumprimento deste dever, por assim dizer sagrado, só pode se realizar com a ajuda de artifícios modificando o aspecto da figura e realizando uma beleza suspeita e fraudulenta. Paradoxalmente, produz-se assim uma unidade abstrata, que assimila a mulher a uma estátua, a um ser divino e superior. Em outras palavras, a mulher deve eternizar, pela maquiagem, aquilo que Baudelaire chama de sua beleza interlope e fetichizar a ela mesma a fim de acusar sua inquietante estranheza e de permitir então ao homem alcançar sua subjetividade. A moda e a maquiagem revelam, através de seu caráter temporal e fugitivo, a eternidade, o intemporal. Em suma, o poético dentro do histórico. A mulher, divinizando-se pelo adorno, torna-se incomunicável como Deus. Assim, apesar e devido a esta nãosemelhança (Les femmes et les filles), ela passa a ser atriz e cortesã. E E no momento preciso em que representa sua feminidade que ela se eterniza aos olhos do homem. Vale dizer que, para Baudelaire, a mulher é por excelência um sujeito moderno, que ela de fato integra a topografia da modernidade.

Ora, toda a teoria do sujeito (e, portanto, toda teoria da modernidade) "estará, sempre, como o ilustrou Luce Irigaray, adaptada ao

7 IRIGARAY, Luco, Speculum, De Pautre fenme. Paris, Minuit, 1974. p.180.

${ }_{0}$ Op, eit. p.714

Ibid. p.717. Grifo mes. 
'masculino'. Ao se sujeitar a isso a mulher renuncia, inconscientemente, à especificidade de sua relação com o imaginário" "9 No entanto, em Água viva, o pintor feminino - ao contrário do pintor da vida moderna - recusa esta objetivação a fim de não participar mais de um mundo cujo princípio de realidade seria confundido com o princípio de realidade fálica. Esta recusa se traduz então, para ela (o pintor feminino), numa escritura que consolida o significante e faz pouco do significado e do referente: "Para te dizer o meu substrato faço uma frase de palavras feitas apenas dos instantes-já. Lê então o meu invento de pura vibração sem significado senão o de cada esfuziante sílaba" (p.11). E mais adiante, ela insiste: "renuncio a ter um significado" (p.26). Este modo de se despojar do conceito com o intuito de afirmar a fenomenalidade não deve, entretanto, levar-nos a ler esta narrativa como se se tratasse de um simples fluxo esquizofrênico. Água viva equivale, como precisa a voz narrativa, a "Ir me seguindo é na verdade o que faço quando te escrevo e agora mesmo: sigo-me sem saber ao que me levará" (p.67). Está ilustrada a impossibilidade de se ter um panorama cognitivo a partir do qual o sujeito feminino e narrador do texto escreveria outra coisa que não fosse a paixão e a matéria da palavra. Se "tenho que ser um objeto, diz a voz narrativa, que seja um objeto que grita" (p.88)

Surge agora uma questão: mergulhar na matéria da palavra não um projeto de escritura totalmente moderno? Pode-se crer que não, na medida em que este acesso à polpa do texto não parece um fim em si que permitisse radicalizar a transgressão, mas antes o efeito de uma experiência da insuficiência da linguagem. Estaria, então, Clarice Lispector (å maneira de Joyce) ${ }^{66}$ fazendo adivinhar o inapresentável na sua própria escritura, no seu significante" e recusando assim - numa atitude bem pós-moderna - o "consolo das boas formas?"10 Neste ponto de vista, o trabalho sobre a língua, sobre a sintaxe, seria um meio de sair da representação, do falogocentrismo e, por fim, da teoria moderna do sujeito (exclusão recíproca do masculino e feminino), como formulou Baudelaire. É a razão pela qual a voz narrativa escreve "tosco e sem ordem [...] redondo, enovelado e tépido, mas às vezes frígido como os instantes frescos" (p.10-11). Definitivamente, ela quer "a desarticulação" jå que suas frases "são feitas na hora mesma em que estão sendo escritas" (p. 84 e 27). Estamos bem longe de $A$ maçã no escuro que, segundo a própria Clarice Lispector, é sua obra mais estruturada. Atravếs do trabalho sobre as modalidades semióticas da língua, o processo de especularização do mesmo e do outro, típico do moderno, encontrase ameaçado. Um novo sistema se impõe, cuja economia discursiva

\section{${ }^{9}$ Op. cit. p.165.}

10 LYOTARD, Jean-François. Le Pastmoderne explique aux enfants. Paris, Galil6e, 1986. p,32. atua muito além da diferença ôntico-ontológica. Trata-se de "subverter a sintaxe, suspendendo sua ordem sempre teleológica"11 para que o desejo deixe de simplesmente ser sinônimo de auto-reflexividade.

Assim se aceita mais o fato de que não possa haver, em Água vi$v a$, início e fim. Sair da linearidade teleológica equivale, então, a entrar em um novo registro da ficção, no meio do qual esta não será mais criada mas nascida. Ora, este registro do neutro se instala no momento da confrontação direta com o Outro. Este cara-a-cara com Deus obriga a voz narrativa a neutralizá-lo através de um processo determinativo: $o$ Deus (p.77), E do Deus (p.74), a ausência do Deus é um ato de religião (p.56 e 57), etc. Entretanto, esta estratégia não parece suficientemente capaz de afastar o pavor que inspira a "Força do que Existe" (p.77), ou seja, aquilo que Clarice Lispector chama de it. Mas o que é o it?

Sem querer categorizar seus atributos, vale no entanto declinar alguns dentre os mais importantes. $\mathrm{O}$ it $\hat{e}$, antes de mais nada, vivo: ${ }^{6} \mathrm{O}$ it vivo é o Deus" (p.31). Por conseqüência, se a voz narrativa apresenta-se a si mesma como it, (p.75), ela é Deus e a força viva do que existe. Mas o it é também a matéria primeira, a inumanidade, o elemento puro, a placenta, o plasma que o pintor feminino deseja tematizar. O Deus só poderá então ser nomeado em uma língua it, língua anterior ao sânscrito. Seu nome: Simptar (a voz narrativa chamando-se Amptala). Mas o it é sobretudo um "aquilo" (p.46), o "aquele" longínquo, a coisa mesma que evoca a distância infinita, "um impessoal de caroço seco e germinativo" (p.30). Como compreender então que as rosas, as abelhas e as formigas não possam ser it? Devemos arriscar a seguinte resposta: só podem aceder ao neutro (o neutro da lingua inglesa) os seres alheios à humanidade. Isto, porque a voz narrativa não estå ainda madura "para falar em "ele" ou "ela" " (p.38). "Inútil querer me classificar: eu simplesmente escapulo não deixando, gênero não me pega mais" (p.13). Neste centro em que age o it, "tenho a estranha impressão de que nảo pertenço ao gênero humano" (p.29).

Estariamos desenovelando a lição trazida pela paixão de G.H. Escapar dos limites do gênero humano equivale a escapar dos limites da dicotomia masculino-feminino. O fora/dentro, o entremeio, a entrelinha que exprimem a escritura de Água viva. Essa operação pela qual o gênero humano não apreende mais nem o sujeito da escritura nem o sujeito da leitura conduz, de fato, à afirmação de que a voz narrativa nunca foi moderna. A partir dai, o não-gênero, o impessoal do instantejă, traz à decifração um enigma cruel, uma "pergunta", um "o quê", entre eu e mim, que não aponta para nada, mas que escorre na água viva. A personalização da voz narrativa só se manterá em Água viva como experiência de humildade: “E se eu digo 'eu’ é porque não ouso di-

\footnotetext{
17 IRIGARAY, Luee, Op, dit, pe177.
} 
zer 'tu', ou 'nós' ou 'uma pessoa'. Sou obrigada à humildade de me personalizar me apequenando mas sou o \&s-tu" (p.13).

$O$ fato de o it possuir um gênero não-gênero permite captarmos a importância dada, em Água viva, à tartaruga: "Para que uma tartaruga? Talvez o título de que estou te escrevendo devesse ser um pouco assim e em forma interrogativa: 'E as tartarugas?' Você que me lê diria: é verdade que há muito tempo não penso em tartarugas" (p.56). A exemplo de todos os seres vivos não-humanos, a tartaruga constitui um "escândalo de admiração". Mesmo que a barata, como assinala Hélène Cixous, nos dê a amarga lição da feiúra, a tartaruga nos ensina pela lentidão, que é preciso subscrever o tempo da vida:

A lentidão: o tempo lento de que precisamos para aproximar, deixar aproximar, tudo, a vida, a morte, o tempo, a coisa; toda a lentidão do tempo que a vida deve ter para se dar sem nos fazer tanto mal, todo o tempo que devemos gastar para atingir a coisa, o outro, para ganhar sem maltratar, para chegar perto. ${ }^{12}$

Isso, a lentidão, frustra a celeridade moderna, porque dilata o tempo do mundo e o deixa expandir-se. Para ser eficiente, a lentidão pressupõe que a tartaruga testemunha a força serena, porque ela carrega o mundo e representa o universo. ${ }^{13}$ Da mesma forma que a barata de A paixxão segundo $G . H$. , a tartaruga pertence à classe dos Dinossauros, cujos membros terrificantes (demus "terrivel", sauros "lagarto") eram de um tamanho gigantesco. Por conseguinte, a voz narrativa de Água viva vive também uma paixão e habita aquilo que ela chama de o "instante-jå", "a pré-história de um futuro". ${ }^{14}$ Assim, na medida em que só o tempo - como essência das coisas - pode lhe fornecer o quadro categórico de suas operações de entendimento, ela estabelece que o espaço ão sura de sua intuição e de sua sensibilidade: ${ }^{6}$ só me comprometo com vida que nasça com o tempo e com ele cresça: só no tempo há espaço para mim" (p.10). A diversidade fenomenal empirica dos "objetos gritantes" que a mulher-pintora deve pensar com suas mãos passa a ser a função de sua própria multiplicidade: "dividome milhares de vezes em tantas vezes quanto os instantes que decorrem, fragmentária que sou e precários os momentos" (p.10). Esta divisão do sujeito feminino o leva a desempenhar as disjunções de forma.

12 Entre Pécriture. Paris, Des Femmes, 1986. p.118-9. Para HElène Cixous, a lentidão e a feiura sẩo as duas grandes lições de viver que nos dá Clarice Lispector. Mas essas liçóes só podem ser recebidas se nós nos lembrarmos de que a fenomenalidade do mundo pre-existe dem ser recebidias

nossas existências. que regeneram e relevam assim o simbolismo lunar. Sua longevidade faz com que a associemos à idéia da imortalidade que faz par com a fertilidade das ẩguas primárias. Acrescentemos também que, para o hermetista Dom Pernety, a tartaruga se apresenta como o simbolo da materia da arte. Tomo evidentemente as figuras simbólicas da tartaruga no Dictionnatre des teria deles de Jean Chevalier e Alain Gheerbrant. Paris, Robert Laffont/Jupitor, 1982

symboles de Jean Chevalier e Alain Gio de Janeiro, Nova Fronteira, 1987, p.103.
A imaginação apreende os fragmentos do mundo sem totalizá-los. Daí que, para Clarice Lispector, a sintaxe a posteriori não constitui nunca uma forma de conhecimento inferior e contingente, e qualquer síntese real a priori não fica independente da experiência.

Ora, a multiplicidade da voz narrativa procede da primazia nãocausal do it: "Qual é o elemento primeiro? Logo teve que ser dois para haver o secreto movimento intimo do qual jorra leite" (p.31). "Logo", ou seja, em seguida, ao mesmo tempo. O it não pré-existe ao diverso, como o simples ao complexo. Ele antes consagra uma época das concepções do mundo em que o feminino existe na totalidade do tempo. Mas como atingi-lo, como sair do velho sonho de simetria entre o feminino e o masculino, entre o ele e o ela? Tomando o caminho de uma vida oblíqua, "oriental", vivida de viés, sobre o modo da lembrança: ${ }^{66}$ Viver essa vida $\varepsilon$ mais um lembrar-se indireto dela do que um viver direto" (p.71). Uma realidade intima vivida de viés: eis a explicação da defasagem, do desacordo que reina entre as coisas. $O$ oblíquo da vida é uma sensação atrás do pensamento, um estado não-divisível atravếs das palavras (p.72), a atualidade gritante, o é que é preciso captar. Aliás, o $e_{\text {, o }} E^{\prime}$ não é a palavra mais importante da língua, o presente do verbo ser? Basta, pois, para se tornar it, que se encontre o próprio é pelo viés da escrita.

Mas a quem esta escrita-it se destina, a quem se dirige? É seu destinatário masculino ou feminino? Estranhamente, a resposta a esta pergunta chega dois parágrafos antes que a voz narrativa confesse nunca ter sido moderna: "Sim, o que te escrevo não é de ninguém. E essa liberdade de ninguém é muito perigosa. É como o infinito que tem cor de $\operatorname{ar}^{\prime \prime}(p, 84)$. E algumas linhas mais adiante, ao encalço da tese sustentada pela mulher-pintora: " $\mathrm{E}$ não escrevo para te agradar. Principalmente a mim mesma. Tenho que seguir a linha pura e manter não contaminado o meu it" (p.85). Não contaminar o it implica que o emissor se desaproprie completamente da escrita. O emissor $\varepsilon$, pois, "personne" (ninguém), nu seja, alguém que seja um ser inumano. Só uma exigência merece ainda ser formulada: escrever com liberdade, sem a menor vigilância. $O$ texto se dá então como uma série de fleches sem liame lógico, como um texto que dribla a tentação falomórfica. É por isso que o destinatário, conforme a voz narrativa, não lerá jamais o que ela escreve, uma vez que o tema $\varepsilon$ atemático e se situa no limite da legibilidade. A experiência da escritura assemelhamse aos esboços que os pintores fazem, e a frase, emudecida por um ritmo musical, permite fotografar cada "instante-ja".

Como não reconhecer aqui, no cerne de Água viva, uma concepçăo da textualidade em que ế preciso "adivinhar o inapresentável na própria escritura, no significante" (Lyotard)? Mas como não reconheeer tambếm que a ineredulidade em relação às grandes metanarrativas 
se dobre, quanto à voz narrativa, numa espécie de nostalgia da origem? Parece-me que esta contigüidade do moderno e do pós-moderno em Água viva traz à tona uma experiência vivida pela literatura brasileira (e, sem dúvida, pela maior parte das literaturas latino-americanas) no seu conjunto. Enquanto sociedade que pertence ao que Furtado chama de "economias periféricas", ${ }^{15}$ o Brasil vivencia uma corrida rumo aos valores da época das Luzes e åqueles trazidos pela promessa de melhoria, baseada no desenvolvimento de uma economia tipicamente capitalista. Mas o Brasil deve assumir, ao mesmo tempo, a presença de forças capazes de precipitar a queda destes valores. Em outras palavras, ao mesmo tempo em que atinge a modernidade, o Brasil se vê confrontado com discursos que deslegitimam o seu devir - situação essa que os países europeus e norte-americanos não tiveram que viver (à parte, fique claro, o Quebéc). Esta contradição fundamental, mesmo não tematizada claramente nos textos de Clärice Lispector (poderíamos pensar também os textos de Osman Lins, Guimarães Rosa, Darcy Ribeiro, João Ubaldo Ribeiro, etc.), pertence a uma axiologia cujos valores, tão logo reconhecidos, mantêm-se ainda sujeitos à reversão. Esta precariedade dos valores que está no cerne de Água viva é trazida pelo sujeito feminino para quem o que importa é descobrir as modalidades pelas quais se pode constituir o ser. Daí uma feminidade moderna que se recusa, paradoxalmente ao "consolo das boas formas".

(Tradução: Michel Sleiman. Revisão de Tradução: Maria do Carmo Campos)

15 Ver, a respeito de noção de economia periférica, FURTADO, Celso, "Les Coonomien peri" pheriques". Encyclopaedia universalis. Symposium: Les enjeux, Paris, Bnoyolopaedia Universalis, 1980. p.960-4. 